\title{
AVALIAÇÃO DA PRODUÇÃO DE BIOSSURFACTANTE UTILIZANTO Pseudomonas aeruginosa ISOLADA DE SOLO CONTAMINADO COM ÓLEO BRUTO OBTIDO NOS CAMPOS PRODUTORES DE SERGIPE
}

\author{
A. M. de LIMA ${ }^{1}$, D. G. S. GOMES ${ }^{1}$ e R. R. de SOUZA ${ }^{1}$ \\ ${ }^{1}$ Universidade Federal de Sergipe, Departamento de Engenharia Química, Laboratório de \\ Biotecnologia \\ E-mail para contato: anita.lima@gmail.com
}

\begin{abstract}
RESUMO - Biossurfactantes são compostos ativos em superfícies produzidos por microrganismos e que têm recebido crescente interesse nas últimas décadas pelas vantagens que possuem sobre os surfactantes químicos. Neste trabalho foram feitos testes com as Pseudomonas aeruginosas utilizando diferentes fontes de carbono e foram quantificados diversos parâmetros para analisar a sua eficiência. As bactérias foram isoladas utilizando solo coletado na praia de Atalaia que foi submetido à contaminação controlada com solução contendo $1 \mathrm{~g} . \mathrm{L}^{-1}$ de óleo bruto oriundo dos campos produtores de Sergipe, com e sem a adição de nutrientes. Nos ensaios para produção de biossurfactante foram testados, utilizando como fontes de carbono, melaço (Mç), vinhaça (V), glicerol (G), manipueira (Mp) e óleo de coco (OC). Os resultados obtidos para Tensão Superficial expresso em mN.m ${ }^{-1}$, foram 41,86 (Mç), 37,78 (V), 36,07 (G), 36,29 (Mp) e 29,31 (OC).
\end{abstract}

\section{INTRODUÇÃO}

O desenvolvimento da biotecnologia está baseado, entre outros fatores, na busca de novos microorganismos e meios de cultura alternativos, com a finalidade de tornar alguns bioprocessos competitivos ou viáveis para produção em grande escala. A economia no processo produtivo é o grande revés na produção de biossurfactante, como no caso da maioria dos processos biotecnológicos. Muitas vezes, a quantidade e o tipo de matéria prima podem contribuir consideravelmente para o custo de produção, visto que a matéria prima representa de 10 a $30 \%$ do custo total de produção em processos biotecnológicos (Cameotra e Makkar, 1998).

Biossurfactantes são moléculas tensoativas que são produzidas a partir de uma variedade de microorganismos. São capazes de baixar a tensão superficial, a tensão interfacial e formação de micro-emulsão, para permitir a mistura de duas soluções não miscíveis. Suas propriedades exibem boa detergência, agentes emulsionantes, dispersantes e de formação de espuma, características que podem ser aplicadas em várias indústrias. (Desai e Banat, 1997).

Pesquisadores no mundo têm isolado bactérias produtoras de bissurfactantes de amostras terrestres e marinhas coletadas em áreas contaminadas com petróleo ou seus derivados, Batista et al. 


\section{9 a 22 de outubro de 2014 \\ Florianópolis/SC}

(2006) selecionaram Bacillus subtilis e Pseudomonas aeruginosa (produtoras de surfactina e ramnolipídeo respectivamente) em diferentes fontes de carbono (glicose, sacarose, frutose e querosene), Romero et al. (1998) isolaram leveduras autóctones e estirpes de bactérias de um córrego contaminado próximo a uma refinaria de petróleo situada em La Plata (Argentina), os autores tinham como objetivo determinar o potencial das bactérias degradadoras de fenantreno (sua única fonte de carbono e energia), Rhodotorula glutinis e Pseudomonas aeruginosa foram os microrganismos predominantes utilizando fenantreno.

As bactérias do grupo Pseudomonas $s p$ são caracterizadas pela sua versatilidade, sendo capazes de sintetizar uma grande quantidade de produtos de interesse industrial como enzimas, piocianina, compostos tenso ativos (ramnolipídeos, viscosina), homoserina lactonas, exopolissacarídeos e polímeros de estoque intracelular (polihidroxialcanoatos - PHA's). Os ramnolipídeos representam uma das principais classes de biossurfactantes, os glicolipídeos, compostos de carboidratos com longas cadeias alifáticas. (Sóberon - Chávez et al., 2005).

A produção de surfactantes a partir de microorganismos - biossurfactante, utiliza os processos fermentativos, e nesse aspecto o custo de produção torna-se elevado, em função dos substratos e nutrientes necessários ao cultivo e desenvolvimento dos microorganismos, além dos processos de recuperação e purificação do produto final. Mukherjee et al. (2006) descreveram o uso de substratos de baixo custo como alternativa econômica e promissora para a produção de biossurfactantes. Derivados de óleo vegetal, substâncias a base de amido, soro de leite, óleo de babaçu e girassol, melaço e efluente de arroz foram utilizados com eficiência na produção de ramnolipídeos e soforolipídeos por vários microrganismos.

Atualmente, as alternativas de valorização de resíduos através do seu aproveitamento tem sido muito incentivadas, já que podem contribuir para a redução da poluição ambiental, bem como permitir a valorização econômica desses resíduos tornando-o um subproduto e deste modo agregando valor ao processo de agroindustrialização (CAMILI, 2007).

O objetivo desse estudo foi avaliar a capacidade de produção de biossurfactante das bactérias do grupo Pseudomonas $s p$ isoladas de solo contaminado com óleo bruto oriundo dos campos produtos do estado de Sergipe, utilizando no substrato potenciais fontes de carbono originadas nos processos produtivos locais como manipueira, óleo de coco e melaço.

\section{METODOLOGIA}

Os experimentos foram conduzidos no Laboratório de Biotecnologia Ambiental no Departamento de Engenharia Química da Universidade Federal de Sergipe - LABAM/DEQ/UFS. As etapas estão descritas nos subitens a seguir.

\subsection{Adaptação das bactérias em ambiente contaminado com óleo}

No processo de obtenção das bactérias adaptadas em ambiente contaminado utilizou-se solo coletado da praia de Atalaia e óleo bruto coletado nos campos produtos de Sergipe. Para essa 
adaptação foram montados sistemas onde foram conduzidos os ensaios de contaminação.

O solo (areia) coletada na praia de Atalaia, foi submetida a secagem ao sol em bandejas plásticas e em seguida peneirado utilizando peneiras da série Tyler, 20 e 60, $84 \mathrm{~mm}$ e $250 \mathrm{~mm}$ de abertura de malha, respectivamente.

Na montagem do experimento foram utilizadas garrafas PET, adaptadas para funcionarem como vasos, ou seja, furadas na base para permitir o escoamento do efluente excedente através do dreno, nesses vasos foram inseridos $500 \mathrm{~g}$ de solo cuja granulometria maior que $250 \mathrm{~mm}$ e menor que 84 $\mathrm{mm}$.

Nos ensaios de contaminação controlada foram preparados soluções que apresentavam concentração de 1 g.L $L^{-1}$ de óleo bruto com e sem adição de nutrientes denominados E2 e E3, respectivamente. Para efeito comparativo ensaios utilizando água destilada (E0) e solução nutritiva (E1) foram conduzidos simultaneamente aos demais experimentos. A composição da solução nutritiva está apresentada na Tabela 1. As aplicações dos efluentes ocorreram de sete em sete dias e o volume aplicado em cada vaso, assim como o volume retido e o volume descartado foram anotados durante o período do experimento.

Tabela 1 - Composição base da solução nutritiva

\begin{tabular}{c|c|c|c}
\hline \multicolumn{2}{|c|}{ Nutriente } & \multicolumn{2}{c}{ Micronutriente } \\
\hline Sais & Concentração $\left({\mathrm{mg} . L^{-1}}^{-1}\right.$ & Elemento & Concentração $\left(\mu \mathrm{g} . \mathrm{L}^{-1}\right)$ \\
\hline $\mathrm{KH}_{2} \mathrm{PO}_{4}$ & 360,0 & Boro & 0,50 \\
\hline $\mathrm{MgSO}_{4}$ & 120,0 & Cobre & 0,02 \\
\hline $\mathrm{CaCl}_{2}$ & 110,0 & Manganês & 0,50 \\
\hline $\mathrm{NH}_{4} \mathrm{NO}_{3}$ & 80,0 & Molibdênio & 0,001 \\
\hline $\mathrm{MgNO}_{3}$ & 86,0 & Zinco & 0,05 \\
\hline & & Ferro & 5,00 \\
\hline
\end{tabular}

Os efluentes foram aplicados nos vasos e o volume descartado era retido no frasco coletor, deste volume foi retirado uma alíquota de $1 \mathrm{~mL}$ e transferida para um erlenmeyer contendo o Caldo Nutriente. Os meios de cultura com as amostras foram submetidos a agitação de $120 \mathrm{rpm}$ e temperatura de $30{ }^{\circ} \mathrm{C}$ em incubadora orbital (shaker), por 24 horas. A partir das amostras incubadas, foram realizadas diluições sequenciais de $10^{-1}, 10^{-2}, 10^{-3}, 10^{-4}, 10^{-5}$ e $10^{-6}$. Para cada diluição, foi utilizada placa de Petri, onde cada placa recebeu $1 \mathrm{~mL}$ da amostra ou diluições em superfície em meio Agar Cetrimida Base, previamente esterilizado em autoclave e distribuído assepticamente em placas de Petri estéreis. As placas foram incubadas a $30{ }^{\circ} \mathrm{C}$ por 48 horas. Após a incubação foi realizada a contagem na placa de colônias formadas e o resultado expresso em Unidade Formadora de Colônia por mililitro de amostra (UFC/mL), de acordo com a Equação 1.

$$
U F C / m L=\frac{n^{0} \text { de colônicas }}{\text { fator de diluição da placa }}
$$


A quantificação indireta de ramnolipídeos foi realizada pela medida de açúcares totais pelo método de Dubois et al.,(1956) mencionado por Santana Filho (2009). A curva de ramnose foi construída utilizando-se uma solução estoque de ramnose (Vetec) padrão com 0,936 mg.mL $\mathrm{mL}^{-1}$.

\subsection{Ensaios fermentativos}

Os ensaios de fermentação foram conduzidos em shaker orbital da marca Certomat BS-T. A velocidade de agitação e a temperatura utilizadas foram de $120 \mathrm{rpm}$ e $30{ }^{\circ} \mathrm{C}$ na obtenção do préinóculo e de $170 \mathrm{rpm}$ e $35^{\circ} \mathrm{C}$ na produção do inóculo e processo fermentativo.

Na preparação do pré-inóculo a cepa preservada foi transferida, utilizando alça de platina, para uma solução de $20 \mathrm{~mL}$ de água destilada com $0,4 \mathrm{~g}$ de peptona bacteriológica a $2 \% \mathrm{~m} / \mathrm{v}$ previamente esterilizada. Em seguida colocada em shaker orbital a $120 \mathrm{rpm}$ a $30^{\circ} \mathrm{C}$ durante 24 horas.

$\mathrm{Na}$ preparação do inóculo foi retirada uma alíquota de $5 \mathrm{~mL}$ do pré-inoculo e transferida para $100 \mathrm{~mL}$ de meio nutriente com a seguinte composição: 10,0 g/L de D-Glicose monohidratado, 5,0 g/L de extrato de levedura em pó, 1,70 g/L de nitrato de amônia $\left(\mathrm{NH}_{4} \mathrm{NO}_{3}\right), 0,20 \mathrm{~g} / \mathrm{L}$ de sulfato de magnésio $\left(\mathrm{MgSO}_{4}\right)$, 7,0 g/L de $\mathrm{Na}_{2} \mathrm{HPO}_{4}$ e 3,0 g/L de $\mathrm{KH}_{2} \mathrm{PO}_{4}$. Em seguida o inóculo foi colocado no shaker por $24 \mathrm{~h}$.

Os ensaios fermentativos foram conduzidos em erlenmeyer de $125 \mathrm{~mL}$ com $50 \mathrm{~mL}$ de volume de meio fermentativo, cuja composição está apresentada na Tabela 2, considerando as fontes de carbono alternativas utilizadas.

Tabela 2 - Composição dos meios fermentativos utilizados nos ensaios

\begin{tabular}{|c|c|c|}
\hline Fonte de carbono & Concentração & $\begin{array}{l}\text { Composição do meio } \\
\text { mineral }\end{array}$ \\
\hline Manipueira & $30 \%(\mathrm{v} / \mathrm{v})$ & \multirow{6}{*}{$\begin{array}{l}\mathrm{NH}_{4} \mathrm{NO}_{3}-1,7 \mathrm{~g} \cdot \mathrm{L}^{-1} \\
\mathrm{MgSO}_{4} \cdot 7 \mathrm{H}_{2} \mathrm{O}-0,2 \mathrm{~g} . \mathrm{L}^{-1} \\
\mathrm{Na}_{2} \mathrm{HPO}_{4}-7 \mathrm{~g} . \mathrm{L}^{-1} \\
\mathrm{KH}_{2} \mathrm{PO}_{4}-3 \mathrm{~g} . \mathrm{L}^{-1}\end{array}$} \\
\hline Óleo de côco & $50 \%(\mathrm{v} / \mathrm{v})$ & \\
\hline Glicerol & $50 \%(\mathrm{v} / \mathrm{v})$ & \\
\hline Vinhaça & $50 \%(\mathrm{v} / \mathrm{v})$ & \\
\hline Óleo bruto & $50 \%$ (v/v) a partir de solução de 1,0 g.L ${ }^{-1}$. & \\
\hline Melaço & $50 \%(\mathrm{v} / \mathrm{v})$ a partir de solução de 10,0 g.. $\mathrm{L}^{-1}$ & \\
\hline
\end{tabular}

Para a medida da tensão superficial foi utilizado um tensiômetro KSV Sigma 700. Utilizando o método em placa de platina iriada denominado placa de Wilhelmy. Com calibração do equipamento no início e no término das análises, medindo-se a tensão superficial da água destilada, o qual encontra-se em torno de $72 \mathrm{mN} . \mathrm{m}^{-1}$.

\section{RESULTADOS E DISCUSSÕES}

\subsection{Contagem das bactérias e produção de ramnose}

O acompanhamento do desenvolvimento de bactérias nos sistemas através da contagem de 
colônias foi realizada no lixiviado obtido após as aplicações dos efluentes propostos - E0, E1, E2 e E3. Na determinação das quantidades de colônias, foi utilizado o meio Cetrimida, que inibe o crescimento de muitos microrganismos, permitindo simultaneamente o desenvolvimento de colônias típicas da Pseudomonas aeruginosa, age como componente quaternário de amônio, detergente catiônico que reduz a tensão na superfície no ponto de contato e tem efeitos precipitantes, complexos e desnaturantes na membrana protéica da bactéria. Apresentando ações inibitórias em uma vasta variedade de microorganismos, incluindo as demais espécies de Pseudomonas, exceto a Pseudomonas aeruginosa. A contagem de microorganismos para cada sistema estudado (E0, E1, E2 e E3) durante o período de avaliação está apresentada na Figura 1 onde pode ser observado com mais clareza o comportamento do desenvolvimento dos microrganismos ao longo do tempo.

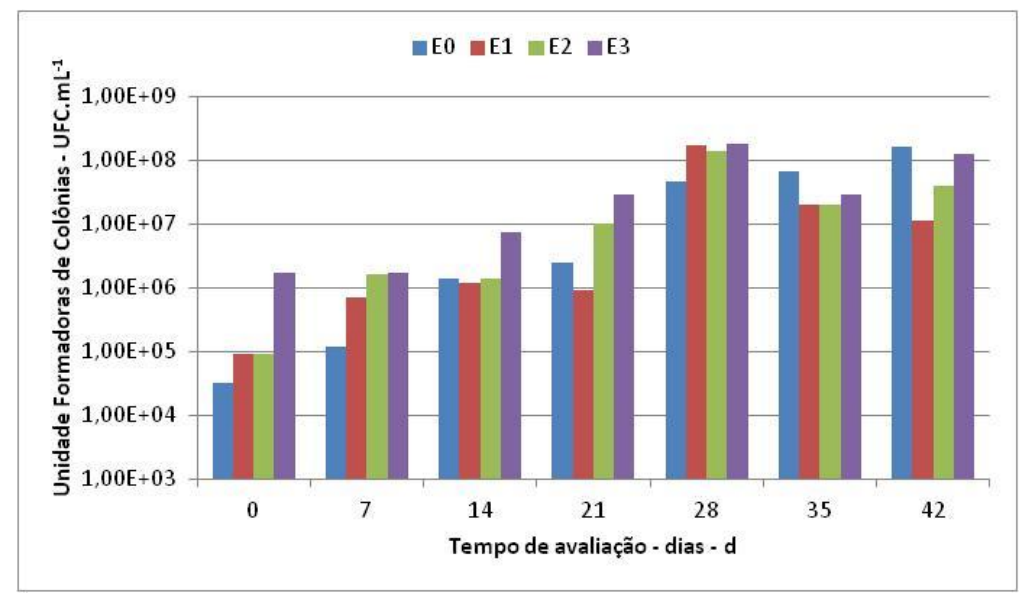

Figura 1 - Contagem de bactérias nos ensaios ao longo do tempo.

Entre os produtos metabolizados pela Pseudomonas sp, ao consumir substrato, estão os ramnolipídeos, que são moléculas de ramnose ligadas a 1 ou 2 moléculas de ácido $\beta$ hidroxidecanóico. Nesse sentido, a quantificação da ramnose concomitantemente a determinação da contagem de colônias, no lixiviado, foi para averiguar a presença desse açúcar, especialmente nos sistemas que receberam os efluentes oleosos (E2 e E3), esse comportamento pode ser visualizado na Figura 2.

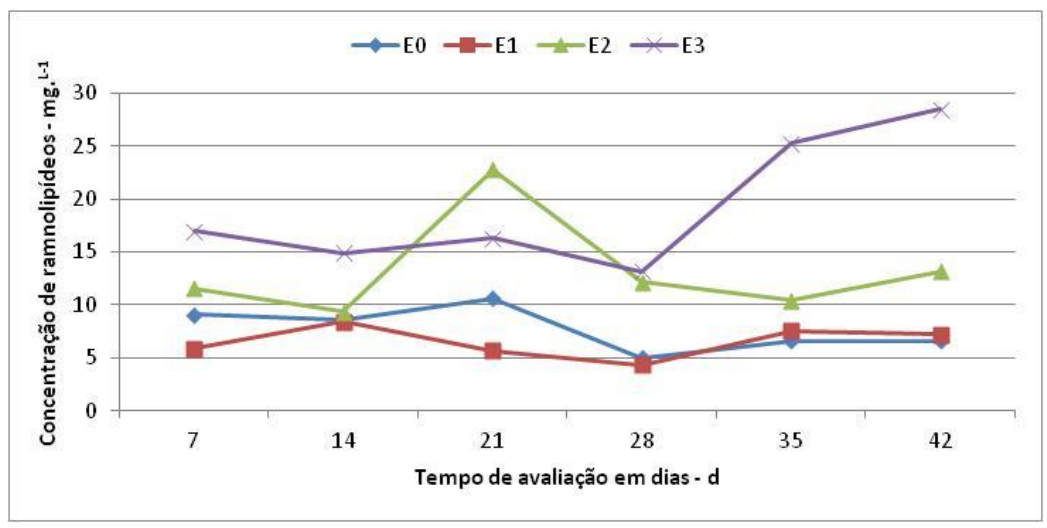

Figura 2 - Avaliação da concentração da ramnose nos ensaios. 


\subsection{Ensaios fermentativos}

A partir da avaliação realizada nos ensaios de contaminação, as bactérias desenvolvidas no ensaio E3, foram testadas quanto a sua capacidade de produção de biossurfactante utilizando fontes alternativas de carbono, nesse sentido as medidas de Tensão Superficial realizadas no caldo fermentado em cada experimento estão apresentadas na Figura 3.

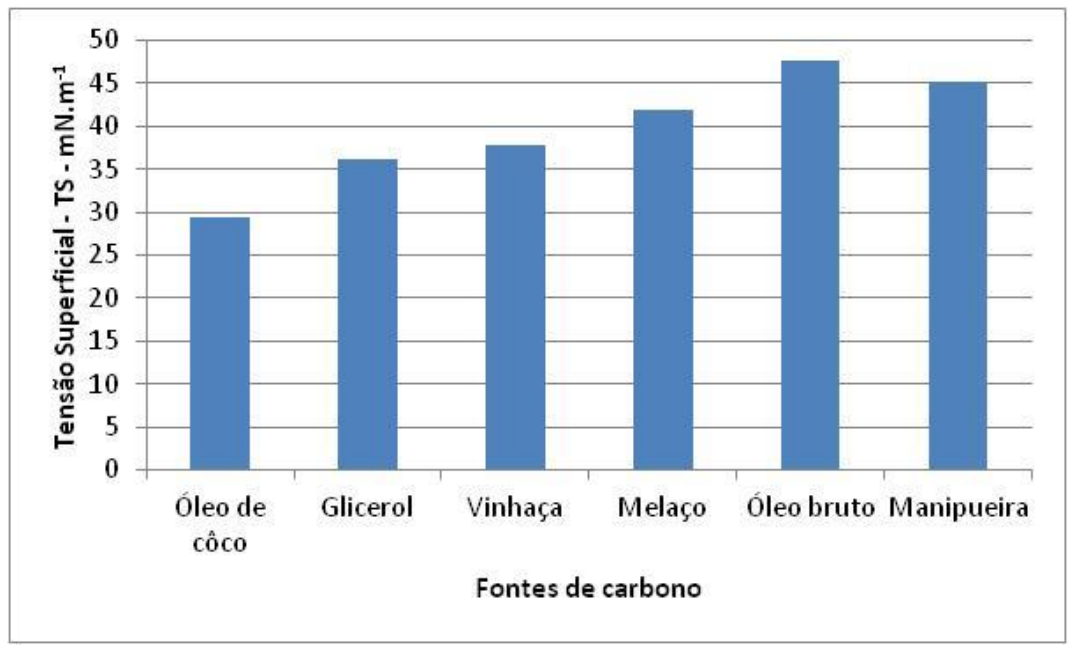

Figura 3 - Avaliação da Tensão Superficial em diferentes fontes de carbono.

Entre as fontes de carbono testadas os ensaios que utilizaram o óleo de côco apresentaram menores valores de tensão superficial $\left(29,31 \mathrm{mN} \cdot \mathrm{m}^{-1}\right)$, indicando que os produtos metabolizados durante a fermentação propiciaram a redução da tensão superficial do meio. Lotfabad et al. (2009) e Yin et al. (2009) realizaram estudos de produção de em cepas de Pseudomonas aeruginosa isoladas em campos produtores de óleo no Iran e em efluentes oleosos na China, respectivamente, utilizando glicose como fonte de carbono e meio mineral obtendo valores de $28 \mathrm{mN} . \mathrm{m}^{-1}$ e $33,9 \mathrm{mN} . \mathrm{m}^{-1}$. Silva et al. (2010) avaliaram a produção de biossurfactante utilizando Pseudomonas aeruginosa UCP0922 utilizando glicerol como fonte de carbono nesse estudo os autores obtiveram valores de tensão superficial $28 \mathrm{mN} \cdot \mathrm{m}^{-1}$ para uma concentração de $2 \%(\mathrm{v} / \mathrm{v})$ de glicerol e $30 \mathrm{mN} \cdot \mathrm{m}-1$ para $7 \%$, no presente estudo utilizamos $50 \%$ (v/v) de glicerol resultando em valores de T.S de $36,07 \mathrm{mN} . \mathrm{m}^{-1}$, a partir do estudo Silva et. al. (2010) há uma indicação que concentrações elevadas de glicerol podem ter um efeito inibidor na produção de biossurfactante.

Outros estudos com cepas de pseudomonas isoladas em solo contaminado foram avaliadas com relação a produção de biossurfactante utilizando substratos alternativos, Bezerra et al. (2012) testaram manipueira a $50 \%$ (v/v) utilizando Pseudomonas aeruginosa isolada nos campos produtores do Rio Grande do Norte obtendo valores de 30,92 mN.m-1 de tensão superficial. Silva et al. (2009) utilizaram óleo bruto a $4 \%$ (v/v) como substrato e cepas de Pseudomonas isoladas em sedimentos de mangue obtendo valores de $30,04 \mathrm{mN} \cdot \mathrm{m}^{-1}$. Bezerra (2006) obteve $31,1 \mathrm{~m} . \mathrm{N} . \mathrm{m}^{-1}$ para tensão superficial em ensaios utilizando $3 \%$ de melaço. 


\section{9 a 22 de outubro de 2014 \\ Florianópolis/SC}

A comparação dos estudos realizados com cepas de Pseudomonas aeruginosa isoladas em áreas contaminadas utilizadas para produção de biossurfactante utilizando substratos alternativos, demonstrou que os valores obtidos utilizando óleo de côco e glicerol foram os que mai se aproximaram mais próximos dos estudos mencionados.

\section{AGRADECIMENTOS}

Gostaríamos de registrar agradecimentos às instituições de fomenta CAPES pela bolsa do Programa Nacional de Pós Doutorada, a COPES/UFS pela bolsa de Iniciação Científica ao LABAM/DEQ/UFS pelo suporte tecnológico.

\section{CONCLUSÕES}

A cepa testada para obtenção de biossurfactante selecionada a partir dos ensaio de contaminação controlado, reduziu a tensão superficial em $29,31 \mathrm{mN} \cdot \mathrm{m}^{-1}$ utilizando óleo de côco como fonte de carbono. Os valores obtidos com os substratos glicerol e vinhaça, 36,07 mN.m ${ }^{-1} \mathrm{e}$ $37,78 \mathrm{mN} \cdot \mathrm{m}^{-1}$, respectivamente, indicam um redução na ordem de $50 \%$ com comparado com a tensão superficial da água destilada que é de $72 \mathrm{mN} \cdot \mathrm{m}^{-1}$. Os valores obtidos para o melaço $\left(41,68 \mathrm{mN} \cdot \mathrm{m}^{-1}\right)$, óleo bruto $\left(47,71 \mathrm{mN} \cdot \mathrm{m}^{-1}\right)$ e manipueira $\left(45,17 \mathrm{mN} \cdot \mathrm{m}^{-1}\right)$, não foram promissores nessa avaliação.

Os resultados obtidos nesse estudo com os microrganismos selecionados no ensaio de contaminação E3, que foi alimentado apenas com solução contendo 1 g.L-1 de óleo bruto, apontam que as bactérias que estavam presentes na areia da praia se adaptaram a fonte de carbono presente na solução fato comprovado pelos valores de 28, $52 \mathrm{mg}$.L ${ }^{-1}$ de ramnolipídeos após 42 dias de ensaio.

\section{REFERÊNCIAS}

BATISTA, S.B.; MOUNTEER, A.H.; AMORIM, F.R.; TÓTOLA, M.R. Isolation and characterization of biosurfactant bioemulsifier-producing bacteria from petroleum contaminated sites. Biorec. Tech. v. 97, p. 868-875, 2006.

BEZERRA, M.S. Levantamento e avaliação de critérios para ampliação de escala da produção de biossurfactantes utilizando melaço como substrato. Dissertação (mestrado), Programa de Pós Graduação em Engenharia Química, Universidade Federal do Rio Grande do Norte, Natal, $101 \mathrm{f}$. 2006.

BEZERRA, M. S.; HOLANDA, V.C.D.; AMORIM, J.A.; MACEDO, G.R; SANTOS, E.S. Produção de biotensoativo utilizando Pseudomonas aeruginosa (P.A) e resíduo agroindustrial (manipueira) como subtrato. Holos. v. 1 (28), p. 14 - 27, 2012.

CAMEOTRA, S.S.; MAKKAR, R.S. Synthesis of biosurfactant in extreme conditions. Appl. Microbiol. Biotechnol. v. 50, p. 520-529, 1998.

CAMILI, E. A. Tratamento da manipueira por processo de flotação sem uso de agentes químicos. Dissertação (mestrado) - Universidade Estadual Paulista, Faculdade de Ciências Agronômicas, Botucatu. 78f. 2007. 
DESAI, J.D.; BANAT, I.M. Microbial production of surfactants and their commercial potential. Microbiol. Mol. Biol. Rev. v. 61 (1), p. 47-64, 1997.

LOTFABAD, T.B.; SHOURIAN, M.; ROOTAAZAD, R.; NAJAFABADI, A.R.; ADELZADEH, M. R.; NOGHABI, K. A.. Na efficient biosurfactant-producing bacterium Pseudomonas aeruginosa MR01, isolated from oil excavation áreas in south of Iran. Coll. and Surf. B: Bioint. v. 69, p. 183193, 2009.

MUKHERJEE S.; DAS P.; SEN R. Towards commercial production of microbial surfactants. Trends Biotechnology, p. 509-515, 2006.

ROMEIRO, M.C. et al. Phenanthrene degradation by microorganisms isolated from a contaminated stream. Environ. Pol.. v. 101, p. 355-359, 1998.

SANTANA FILHO, A. P. Ramnolipídeos produzidos por Pseudomonas aeruginosa UFPEDA 614: estudos de produção e de variação da composição de homólogos. Dissertação (mestrado). Pós Graduação em Ciências-Bioquímica, Universidade Federal do Paraná. Curitiba, 87 f., 2009.

SILVA, S.N.R.L.; FARIAS, C.B.B.; RUFINO, R.D.; LUNA, J.M.; SARUBBO, L.A.Glycerol as substrate for the production of biosurfactant by Pseudomonas aeruginosa UCP0992. Coll. and Surf. B: Bioint. v. 89, p. 174-183, 2010.

SILVA, T.A.L.; ARAÚJO, H.W.C.; TAMBOURGI, E.B.; SILVA, C.A.A.; TAKAKI, G.M.C. Potencial biotecnológico de uma nova linhagem de Pseudomonas fluorescens na produção de biossurfactante utilizando petróleo como substrato. Exacta. v. 7, n. 1, p. 31 - 37, 2009.

SOBERON-CHAVEZ, G.; LEPINE, F.; DEZIEL, E. Production of rhamnolipids by Pseudomonas aeruginosa. Applied Microbiol. Biotechnol. v. 68, p. 718-725, 2005.

YIN, H.; QIANG, J.; JIA, Y.; YE, J.; PENG, H.; QIN, H.; ZHANG, N.; HE, B. Characteristic of biosurfactant produced by Pseudomonas aeruginosa S6 isolated oil-containing wastewater. Proc. Bioch. v. 44, p. 302-308, 2009.

MAKKAR, R.S., CAMEOTRA, S.S. An update on the use of unconventional substrates for biosurfactant production and their new applications. Appl. Microbiol. Biotechnol. v. 58, p. 428-434, 2002. 